\title{
UMA CARTA INÉDITA DE BAUdELAIRE A Charles Asselineau [?], 9 DE MAIO DE 1853
}

\section{Andrea Schellino}

Uma carta inédita de Baudelaire foi posta à venda em Paris, dia 12 de dezembro de 2016, no Hotel Ambassador. Eis o texto, estabelecido conforme o fac-símile publicado no catálogo Lettres (2016, pp. 6-7):

Versalhes, segunda-feira, 9 de maio de 1853.

Meu caro amigo,

Eu reclamo a cortesia que você me ofereceu. Boyer não retornou ontem à noite; - percebi que há hoje CONFERÊNCIA NO ATHÉNÉE, e Amanhã PRELEÇÃO NO ATHÉNÉE; é alarmante. Boyer me lembra aquelas mulheres que estão menstruadas todos os dias, e das quais não se pode jamais apalpar o rabo. No caso dele, agora tem o Athénée todos os dias. - Tenho certeza de que não há dinheiro para mim na Dama com papel timbrado, mas sei que minha mãe está em Paris, e que deseja ver-me dia 10, Amanhã.

- Seria muito amável de sua parte você mesmo vir, mas, em todo caso, você sabe que não se pode enviar um título de menos de cinco francos.

Todo seu e mil perdões,

Ch. Baudelaire

Enfim, este incompreensível gracejo vai Finalmente acabar. 


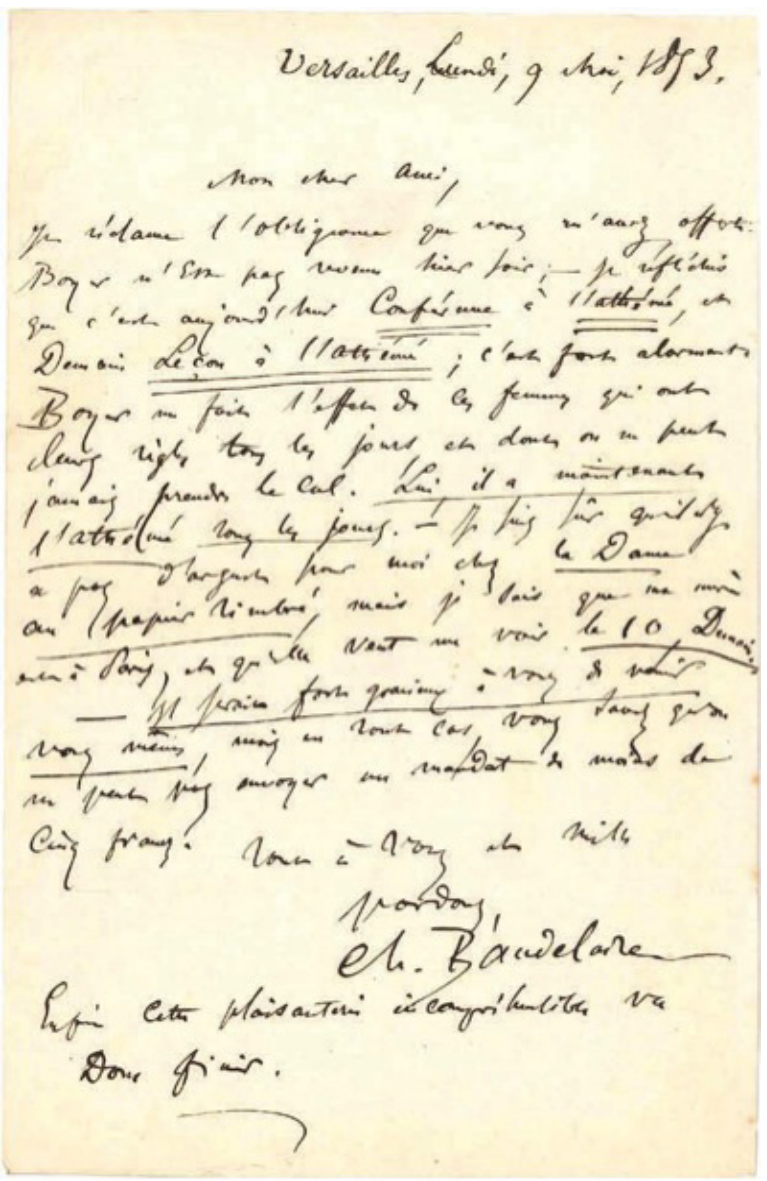

Essa carta, que tinha pertencido ao bibliófilo e historiador Alfred Bégis, já havia sido posta à venda pública no hotel Drouot, em maio de 1910, mas os peritos haviam julgado o conteúdo por demais licencioso para publicá-la: "Carta curiosa, curiosa demais, dirigida a um amigo, e que não poderíamos publicar em sua integralidade" (CATALOGUES, 1910, [s.p.]). ${ }^{1}$ Em sua edição da Correspondance de Baudelaire (1973, CPl I, p. 224), Claude Pichois, que assinala a existência dessa carta, emite a hipótese de que Charles Asselineau seja o destinatário.

Nascido em Cahors em 1829, Philoxène Boyer havia conquistado a simpatia e estima de algumas celebridades literárias parisienses, dentre

\footnotetext{
1 "Lettre curieuse, trop curieuse, adressée à un ami, et qu'on ne pourrait imprimer en entier". 
elas Nerval, Hugo e Gautier. Escritor e conversador muito fecundo, havia se relacionado com Baudelaire bem no início dos anos cinquenta. Acabava, em alguns meses, de dilapidar a herança materna e de adquirir uma reputação de prodigalidade. Boyer tinha disposto de seus meios a serviço de sua paixão de orador (PICHOIS, 2005, p. 381).

$\mathrm{Na}$ primavera de 1853 , Boyer, conferencista impenitente, proferiu conferências no Athénée National de Paris, no local inaugurado um ano antes na praça Vendôme, no 12 . Um público de associados assistia aulas sobre diversos assuntos científicos ou literários, e frequentava a biblioteca conexa a esse Athénée, na rua de Valois, no 8. No dia 20 de abril, uma centena de pessoas assistiram à primeira conferência de Boyer sobre as Memórias de além-túmulo. Nos dias 21 e 22 de abril (CPl I, pp. 220-221), Baudelaire apressou-se em convidar seus amigos em comum, Champfleury e Maxime Du Camp, para a próxima leitura. Alguns dias depois, os jornais saudaram o evento. Dia 25 de abril, Gautier, nas colunas do La Presse, louvou a eloquência do conferencista:

O Sr. Philoxène Boyer comenta no Athénée, perante um auditório numeroso, as Memórias de Chateaubriand que tomou como texto para improvisações panorâmicas, repletas de engenhosas relações, percepções inesperadas, considerações estéticas e morais do mais alto interesse. A análise dessa magnífica obra é como o ponto de partida de um curso de literatura moderna que ninguém além do Sr. Philoxène Boyer, poeta e erudito, seria capaz de ministrar (GAUTIER, 1853, p. 2).

Ao agradecer Gautier pelo seu apoio, Philoxène Boyer lhe anuncia que tem a intenção de falar, na sua próxima preleção, "da América, de Washington e, melhor ainda, de Charlotte Ives, Bettina, Graziella, Modeste Mignon"2 (GAUTIER, 1991, p. 178).

Mas o que faziam Baudelaire e Boyer em Versalhes, no final de abril ou início de maio de 1853? Em memórias recolhidas em 1906 por Jacques Crépet, Asselineau (1906, pp. 294-295) contou o seguinte episódio:

No tempo do despotismo de Philoxène, Baudelaire não foi menos poupado do que outros: nunca fiquei tão surpreso como ao ver aquela natureza tão rígida, tão contundente, quase sempre independente até a ferocidade, ceder perante um conversador cuja força toda residia em sua língua e nervos. Baudelaire acabou aterrorizado: "cruel pequeno lírico" (era o nome que dava a Philoxène). "Infame pequeno lírico!" Ao entrar na minha casa ele perguntava: "O Sr. Boyer está?”. E mais de uma vez se esquivou para não ter que suportar sua presença. Philoxène fez mais do que atordoá-lo com sua tagarelice. Uma vez ele o reteve

2 Carta de Philoxène Boyer a Gautier[, aproximadamente 25 de abril de 1853].

Remate de Males, Campinas-SP, v. 37, n. 1, pp. 479-484, jan./jun. 2017 
durante um mês em Versalhes, num albergue onde tinham conseguido crédito, partindo sempre para ir buscar dinheiro em Paris, e nunca trazendo um centavo de volta. Guardei duas ou três cartas lamentáveis que Baudelaire escreveu naquela ocasião, rogando-me por libertá-lo. ${ }^{3}$

Segundo Henri Girard (1921), ${ }^{4}$ Baudelaire e Philoxène Boyer tinham previsto visitar Émile Deschamps, que morava em Versalhes. No dia seguinte de sua visita a Deschamps, os dois escritores teriam se perdido no bosque de Versalhes, antes de se instalarem em um confortável hotel da cidade. Logo teriam percebido que não tinham como pagar a conta.

Para apoiar sua história, Henri Girard publicava uma carta de Boyer a Émile Deschamps:

Caro Mestre,

Eis um acidente que ocorreu ao meu amigo Baudelaire e eu. Nós nos deixamos levar pelo grande charme melancólico de Versalhes, que para nós sua poesia duplicou mais de uma vez, e que sua hospitalidade há pouco engrandecia.

Tendo partido para um passeio de algumas horas, aqui estamos ao final de nosso segundo dia de ausência. Parecemos um capítulo de Gil Blas - e em todos os aspectos. Isso explica que recorramos sem pudor à sua benevolência, que jamais falhou com ninguém, - que estamos em um hotel onde não sabemos como saldar nossas pequenas despesas - que somos forçados a passar novamente a noite em sua boa cidade... e que no final das contas ficaríamos mais do que agradecidos se pudesse enviar por portador algum dinheiro - o suficiente para nos livrar da situação. - Depois de amanhã, o dinheiro lhe será devolvido e eu juntarei ao envio minhas últimas pequenas obras. Mas o que não devolverei, éa minha gratidão e minha devoção que preservo apenas para mim e para sempre.

Philoxène Boyer

(GIRARD, 1921, p. 520).

Dia 1ํ- de setembro de 1924, no Le Journal, Émile Geidan deu uma versão diferente desse episódio versalhês. Baudelaire e Boyer teriam planejado ir até Versalhes para "elaborar uma história de Luis XIV, tomando como base de [seu] trabalho, a vida e os atos dos diferentes personagens cujos retratos ilustram as galerias do castelo" (GEIDAN, 1924, p. 4). Hospedados em um hotel de Versalhes, Baudelaire e Boyer teriam rapidamente esgotado seus recursos e teriam sido obrigados a deixar suas bagagens em garantia. Baudelaire teria então se refugiado em uma casa de passe, aguardando receber o dinheiro necessário para pagar suas dívidas.

3 Reedição em Crepet \& Pichois (1953, pp. 186-187).

4 Henri Girard (1921; reimpr. 1977, p. 519). Ele situa equivocadamente o episódio em 1860. Ver também Sylvain-Christian David (1987, p. 173).

Remate de Males, Campinas-SP, v. 37, n. 1, pp. 479-484, jan./jun. 2017 
Quinze dias depois de sua partida para Versalhes, Boyer volta a Paris. Ele suplica a Émile Geidan e seus amigos que lhe concedam algum recurso financeiro para pagar sua conta de hotel, recuperar suas bagagens e liberar Baudelaire, retido no bordel. O desfecho dessa peripécia é contado por Geidan (1924, p. 4):

Philo partiu. Nossa surpresa foi extrema quando vimo-lo, três dias depois, reaparecer.

- Eu retornei a Versalhes, confiou-nos, levando uma quantia insuficiente. Mal recebido por Baudelaire, este me diz: "Fique aqui, estarei de volta de noite". Ora, ele não reapareceu mais, e meus anfitriões me botaram na rua como um criminoso. Cheguei de Versalhes a pé, extenuado e morrendo de fome.

Conforme uma carta à Sra. Aupick, do dia 14 de maio de 1853, Baudelaire pôde finalmente deixar Versalhes dia 11 (CPl I, p. 226). ${ }^{5}$

Aquele dia conturbado foi, para o poeta, fecundo. É de Versalhes que Baudelaire, dia 3 de maio, envia Reversibilidade à $\mathrm{M}^{\mathrm{me}}$ Sabatier e, dia 9 de maio, Confissão; e é também de lá que lhe endereça $A$ aurora espiritual, ${ }^{6}$ alguns dias depois, "after a night of pleasure and desolation" (CPl I, p. 224), ocorrida numa casa de passe de Versalhes.

Tradução de Gilles Jean Abes

Revisão de Eduardo Veras

\section{REFERÊNCIAS BIBLIOGRÁFICAS}

ASSELINEAU, Charles. Recueil d'anecdotes. In: CREPET, Jacques (ed.). Charles Baudelaire. Étude biographique d'Eugène Crépet, suivie des Baudelairiana d'Asselineau. Paris: A. Messein, 1906.

BAUDELAIRE, Charles. Correspondance. 2v. Texte établi, présenté et annoté par Claude Pichois avec la collaboration de Jean Ziegler. Paris: Gallimard, 1973. (Coll. Bibliothèque de la Pléiade)

BAUDELAIRE, Charles. Lettres à sa mère. Correspondance établie, présentée et annotée par Catherine Delons. Paris: Manucius, 2017.

5 Foi Catherine Delons, em sua recente edição das cartas de Baudelaire à $M^{\text {me }}$ Aupick, quem estabeleceu que essa carta não foi enviada de Versalhes, mas de Paris (BAUDELAIRE, 2017, p. 124).

6 Trata-se da hipótese de Jean-François Delesalle (1969, p. 11).

Remate de Males, Campinas-SP, v. 37, n. 1, pp. 479-484, jan./jun. 2017 
CATALOGUE DE la bibliothèque de feu M. Alfred Bégis, terceira parte, № 1.334. Paris, Hôtel Drouot. Peritos: Émile Paul et fils e Guillemin. 27 de maio de 1910.

CREPET, Jacques \& PICHOIS, Claude (orgs.). Baudelaire et Asselineau (edition critique). Paris: Nizet, 1953.

DELESALLE, Jean-François. La trace de quelques documents baudelairiens. Bulletin baudelairien, v. IV, no 2, 9 avr. 1969, pp. 7-12.

GAUTIER, Théophile. Théâtres. La Presse, Feuilleton, 25 de abril de 1853, pp. 1-2.

GAUTIER, Théophile. Correspondance générale, t. V. Éditée par Claudine LacosteVeysseyre, sous la direction de Pierre Laubriet. Genève: Droz, 1991, p. 178.

GEIDAN, Émile. Vieux souvenirs d'un étudiant de 1852. Baudelaire. Murger, Banville, Philoxène Boyer. Le Journal, Le Magazine Littéraire, º sept. 1924, p. 4.

GIRARD, Henri. Un bourgeois dilettante à l'époque romantique, Émile Deschamps 17911871. Paris: Édouard Champion, 1921.

GIRARD, Henri. Un bourgeois dilettante à l'époque romantique, Émile Deschamps 17911871. Genève: Slatkine Reprints, 1977.

LETTRES ET manuscrits autographes, № 16. Paris, Hôtel Ambassador, Salon Mogador, Maison de ventes aux enchères Alde. Perito: Thierry Bodin. 12 de dezembro de 2016, pp. 6-7.

PICHOIS, Claude \& ZIEGLER, Jean (1987). Charles Baudelaire. Paris: Fayard, 2005.

DAVID, Sylvain-Christian. Philoxène Boyer. Un sale ami de Baudelaire. Paris: Ramsay, 1987. 